\title{
Barriers to Cataract Surgery in Peri-urban Regions of Eastern Nepal
}

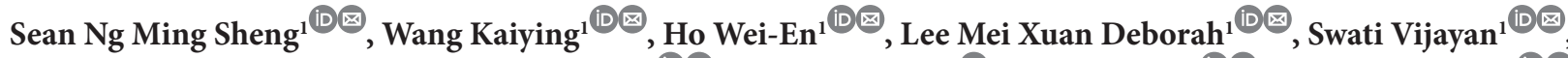

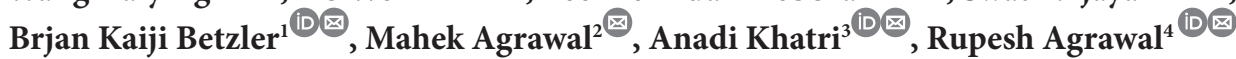 \\ ${ }^{1}$ Lee Kong Chian School of Medicine, Nanyang Technological University, Singapore \\ ${ }^{2}$ Saint Joseph's Institution International School \\ ${ }^{3}$ Department of Ophthalmology, Birat Medical College and Teaching Hospital, Morang, Nepal \\ ${ }^{4}$ National Healthcare Group Eye Institute, Tan Tock Seng Hospital, Singapore
}

\begin{abstract}
Introduction: Despite cataract being a condition easily treated by surgery, it continues to be the leading cause of blindness worldwide (35.15\%). In Nepal, the proportion of blindness due to cataract is much higher, with cataract accounting for $62.2 \%$ of all blindness. An effective method of decreasing this figure is by addressing the main barriers preventing people from accessing cataract surgery. Knowing that these barriers are dynamic and region-specific, our study aimed to determine the current barriers faced in Morang and Sunsari districts of Nepal.
\end{abstract}

Materials and methods: Subjects were patients attending a cataract surgical camp, who had unilateral or bilateral blindness due to cataract. A survey was administered to determine the factors contributing to their delay in receiving treatment for cataract. Furthermore, the percentages of male and female subjects with bilateral blindness receiving treatment at the surgical camp were compared to the percentage of males and females with bilateral blindness due to cataract in Morang and Sunsari.

Results: The main barriers for both subjects with unilateral and bilateral blindness were the inability to afford treatment and the lack of awareness that cataract is treatable. Additionally, although more women were bilaterally blind due to cataract compared to men in Morang and Sunsari, men were more likely to receive treatment compared to women.

Conclusion: Policies targeted at reducing costs of surgery, increasing the awareness of cataract surgery, and specifically increasing women's access to cataract surgery would be effective methods in decreasing the prevalence of avoidable blindness due to cataract in Morang and Sunsari.

Key words: Barriers, Cataract, Nepal, Surgery.

$\begin{array}{ll}\text { Financial Interest : Nil } & \text { Received : 02.03.2020 } \\ \text { Conflict of Interest : Nil } & \text { Accepted : 06.12.2020 } \\ \text { Corresponding Author } & \\ \text { Dr. Rupesh Agrawal } & \\ \text { National Healthcare Group Eye Institute, } & \\ \text { Tan Tock Seng Hospital, Singapore. } & \\ \text { E-mail: rupeshttsh@gmail.com } & \end{array}$

Access this article online

Website: www.nepjol.info/index.php/NEPJOPH

DOI: https://doi.org/10.3126/nepjoph.v13i2.31731

Copyright $\odot 2021$ Nepal Ophthalmic Society

ISSN: 2072-6805, E-ISSN: 2091-0320

Tan Tock Seng Hospital, Singapore.

This work is licensed under a Creative Commons

Attribution-NonCommercial-NoDerivatives 4.0

International License (CC BY-NC-ND). 


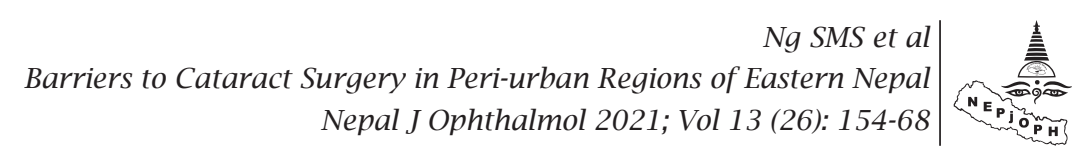

\section{INTRODUCTION}

Despite major advancements to eliminate avoidable blindness as per the World Health Organisation (WHO) VISION 2020 Global Initiative within the past decade (World Health Organisation, 2020), the global burden of cataract remains large and ever growing. Amongst the world population in 2015, cataract was the leading cause of blindness (12.6 million, $35.15 \%$ ) and the second largest cause of moderate to severe vision impairment (52.6 million, 25.15\%). By 2020, it is estimated that these figures will increase to 13.4 million and 57.1 million respectively (Flaxman et al, 2017). In Asia, similar findings were reported, with cataracts and under-corrected refractive errors making up the two most common causes of blindness (Wong et al, 2006).

In Nepal, $62.2 \%$ of all blindness has been reported to be caused by cataract, a figure significantly higher than the global average of 35.2\% (Flaxman et al, 2017; Sapkota et al, 2012). Furthermore, although cataract surgical coverage in Nepal has increased from 35.0\% in 1981 to $84.6 \%$ in 2006-2010 (Sapkota et al, 2012; Gray et al, 2015; Brilliant et al, 1985), the improvements have been disproportionate, with urban populations having greater access to surgery compared to rural populations (Sapkota et al, 2012). Thus, a significant proportion of the population in rural regions of Nepal still lack access to treatment for cataract. This demonstrates that much still needs to be done to tackle cataract-caused blindness in the country.

Increasing cataract surgical coverage does not only improve the eye health of the population, but additional studies have shown that increasing access to cataract surgeries for older adults in low-income settings leads to increased amounts of time spent on productive activities with decreased time spent on inactivity and also decreased need for assistance with more self-dependence (Polack et al, 2010), leading to positive impacts on the well-being and inclusion of recipients. Therefore, increasing access to cataract surgeries is paramount, as it serves to improve the general eye health of the population and also has additional positive economic and social outcomes.

In Nepal, Epidemiology of Blindness study in 2012 (Sapkota et al, 2012), it was noted that there was a high degree of variation in the barriers to cataract surgery reported by different regions of the country. Given this variation, individual studies identifying the barriers to cataract surgery, specific to distinct regions, need to be conducted. Once these region-specific barriers are identified, they can be addressed using targeted policies to increase regional cataract surgical coverage, ultimately leading to the goal of decreasing the prevalence of avoidable blindness due to cataract in Nepal.

The aim of this study was therefore to explore and determine the barriers to cataract surgery faced by people with blindness in Morang and Sunsari districts of Eastern Nepal. 


\section{MATERIALS AND METHODS}

Patients attending a free-of-charge cataract surgical camp in Biratnagar, Nepal, were recruited to be the subjects of this qualitative study done over 3 days. Outreach programmes for the surgical camp were held in rural villages in Morang and Sunsari Districts of Province Number One, where villagers were screened for visual impairment. Patients with cataract were transported to Birat Eye Hospital for surgery.

Subjects for the study were recruited after patients had finished their post-operative consult, one day after the surgery was conducted. After explaining the purpose of the survey and obtaining consent from subjects, we asked patients a defined set of questions from our survey questionnaire (sample found in appendix) through translators. Questions include why they had not had surgery done prior to this camp, whether they knew the causes of cataract, and whether they were aware of the treatments for cataract prior to the outreach programmes of this surgical camp. Data of the subject's presenting visual acuity were also collected.

The definition of blindness used by the World Health Organization (WHO), according to the International Statistical Classification of Diseases and Related Health Problems [Tenth Revision] (2016), and the definition of blindness used in Nepal are different. Specifically, the WHO defines blindness as a visual acuity of less than $3 / 60$ in the better eye with best possible correction while in Nepal, blindness is defined as a visual acuity of less than 6/60 in the better eye with correction (Sapkota et al, 2012). The categorization of levels of visual impairment are shown in Table 1.

In order to facilitate comparisons between data from international studies that use the WHO definition $(\mathrm{VA}<3 / 60)$ and Nepal-based studies that use the Nepal definition (VA $<6 / 60$ ), the results of this study will be presented using both the WHO definition of blindness $(\mathrm{VA}<3 / 60)$ as well as the Nepal definition of blindness (VA $<$ $6 / 60)$.

Table 1: A comparison between the categorization of visual impairment with regards to visual acuity by the World Health Organization and Nepal.

\begin{tabular}{|l|l|l|}
\hline Visual Acuity & ICD-10 Definition & Nepal Definition \\
\hline VA $\geq 6 / 18$ & 0 Mild or no visual impairment & Mild or no visual impairment \\
\hline VA $<6 / 18$ & 1 Moderate visual impairment & Visual impairment \\
\hline VA $<6 / 60$ & 2 Severe visual impairment & Blindness (Economic Blindness) \\
\hline VA $<3 / 60$ & 3 Blindness & Blindness (Social Blindness) \\
\hline VA $<1 / 60$ & 4 Blindness & Blindness (Manifest Blindness) \\
\hline No light perception & 5 Blindness & Blindness (Absolute Blindness) \\
\hline
\end{tabular}


When administering the survey, all subjects, regardless of presenting visual acuity, were asked if they knew the causes and treatments of cataract. However, only subjects who had a presenting visual acuity of $<6 / 60$ were asked for reasons why they had not yet received treatment prior to this surgical camp. Results collected for the barriers to cataract surgery faced by subjects were first categorized using both the WHO and Nepal definitions of blindness, followed by whether subjects were unilaterally blind or bilaterally blind. Subjects were also categorized based on gender.

The data collected from our survey was analysed using Microsoft Excel 2016. Following the collection of data for the barriers to cataract surgery cited by subjects, we separated the data based on the gender of subjects. Following this, we categorized data based on whether subjects were unilaterally blind or bilaterally blind, using both the WHO definition (VA $<3 / 60$ in the better eye with best correction) and the Nepal definition of blindness (VA $<6 / 60$ in the better eye with best correction). The number of each barrier cited was tabulated and ranked in descending order of frequency. Using Excel, the percentages for each barrier cited were calculated. We then compared the percentages of each barrier to those published in past literature in order to investigate if and how the barriers faced by the population of Morang and Sunsari have changed over the past few years.

The results for the barriers to cataract surgery cited by subjects will be presented in 4 categories. These categories include 1) Unilateral Blindness (WHO definition, VA $<3 / 60$ in the better eye with best correction), 2) Unilateral Blindness (Nepal definition, VA $<6 / 60$ in the better eye with best correction), 3) Bilateral Blindness (WHO definition, VA $<3 / 60$ in the better eye with best correction), and 4) Bilateral Blindness (Nepal definition, $\mathrm{VA}<6 / 60$ in the better eye with best correction). Within these categories, results are further subcategorized based on gender. Lastly, the results for awareness of the causes of and treatment for cataract are also presented.

\section{RESULTS}

A total of 155 [72 (46.45\%) male and 83 (53.55\%) female] subjects participated in the study. Male subjects were between 40 and 84 years of age $($ mean $=63.5, \mathrm{SD}=9.78)$ and female subjects were between 40 to 80 years of age (mean=61.2, $\mathrm{SD}=9.27$ ). Subjects lived in rural villages of the Morang and Sunsari districts in Province Number One, Nepal.

\section{Barriers to Cataract Surgery}

Unilateral Blindness (WHO definition, visual acuity $(V A)<3 / 60$ in one eye, with visual acuity in better eye $\geq 3 / 60$ )

In male subjects with unilateral blindness (VA $<3 / 60$ ), the main reasons identified were the inability to afford treatment (68.57\%), unawareness of treatment (11.43\%), and geographical reasons such as lack of transport to the hospital or having to travel long distances 
to the hospital (11.43\%). Other reasons include having no one to accompany them (5.71\%), waiting for a surgical camp (5.71\%), having adequate vision in one eye $(2.86 \%)$, health problems preventing them from going to the hospital (2.86\%), waiting for their previous cataract operation to heal (2.86\%), lack of time (2.86\%), waiting for the winter season $(2.86 \%)$, and misconceptions about treatment leading to fear of surgery $(2.86 \%)$.

In female subjects with unilateral blindness (VA $<3 / 60$ ), the main barriers identified were the inability to afford treatment $(60.47 \%)$, unawareness of treatment (20.93\%), and lack of escort to the hospital (11.63\%). Other reasons include waiting for cataract to mature (11.63\%), adequate vision in one eye $(4.65 \%)$, health problems preventing them from going to the hospital (4.65\%), lack of transport or having to travel long distances to the hospital $(4.65 \%)$, feeling that treatment was unnecessary $(4.65 \%)$, waiting for a surgical camp (2.33\%), and not knowing how to get surgery $(2.33 \%)$.

These results are presented in Table 2 and Figure 1.

Table 2: The numbers and percentages of each barrier cited by patients with unilateral blindness according to the WHO definition of blindness $(\mathrm{VA}<3 / 60)$.

\begin{tabular}{|l|c|c|c|c|c|c|}
\hline \multirow{2}{*}{\multicolumn{1}{|c|}{ Barriers }} & \multicolumn{2}{c|}{ Male (n=35) } & \multicolumn{2}{c|}{ Female (n=43) } & \multicolumn{2}{c|}{ Total (n=78) } \\
\cline { 2 - 7 } & $\mathbf{n}$ & $\mathbf{\%}$ & $\mathbf{n}$ & $\mathbf{\%}$ & $\mathbf{n}$ & $\mathbf{\%}$ \\
\hline Cannot afford & 24 & 68.57 & 26 & 60.47 & 50 & 64.10 \\
\hline Unaware of treatment & 4 & 11.43 & 9 & 20.93 & 13 & 16.67 \\
\hline Hospital was too far away/ No transport & 4 & 11.43 & 2 & 4.65 & 6 & 7.69 \\
\hline No company & 2 & 5.71 & 5 & 11.63 & 7 & 8.97 \\
\hline Waiting for surgical camp & 2 & 5.71 & 1 & 2.33 & 3 & 3.85 \\
\hline Adequate vision in one eye & 1 & 2.86 & 2 & 4.65 & 3 & 3.85 \\
\hline Health problems & 1 & 2.86 & 2 & 4.65 & 3 & 3.85 \\
\hline Fear of operation & 1 & 2.86 & 0 & 0.00 & 1 & 1.28 \\
\hline No time & 1 & 2.86 & 0 & 0.00 & 1 & 1.28 \\
\hline Waiting for previous cataract surgery to heal & 1 & 2.86 & 0 & 0.00 & 1 & 1.28 \\
\hline Waiting for winter & 1 & 2.86 & 0 & 0.00 & 1 & 1.28 \\
\hline Waiting for cataract to mature & 0 & 0.00 & 5 & 11.63 & 5 & 6.41 \\
\hline Felt that treatment was unnecessary & 0 & 0.00 & 2 & 4.65 & 2 & 2.56 \\
\hline Unaware of how to access treatment & 0 & 0.00 & 1 & 2.33 & 1 & 1.28 \\
\hline
\end{tabular}




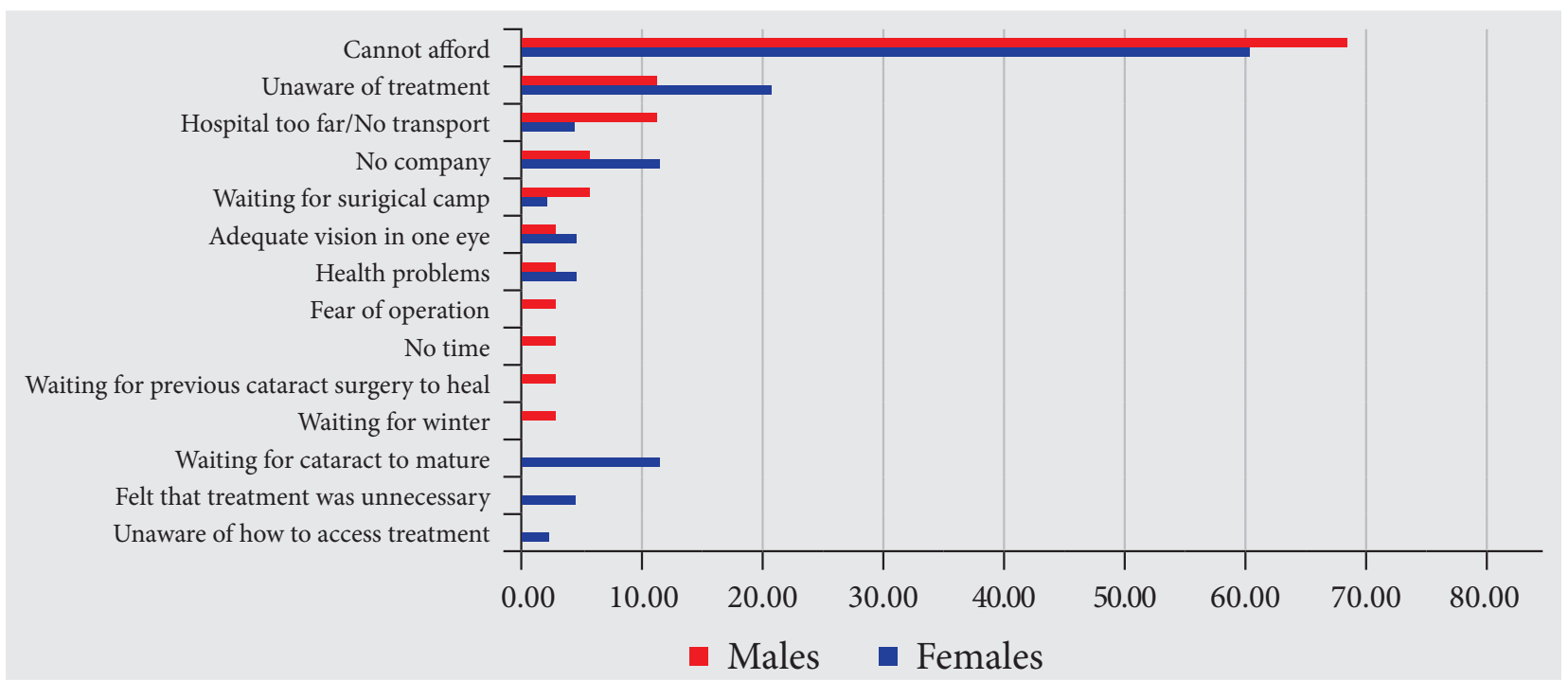

Figure 1: Comparison between the percentages of each barrier cited by male and female subjects with unilateral blindness according to the WHO definition of blindness (VA $<3 / 60)$.

Unilateral Blindness (Nepal definition, visual acuity $(V A)<6 / 60$ in one eye, with visual acuity in better eye $\geq 6 / 60$ ).

In male subjects with unilateral blindness (VA $<6 / 60$ ), the main reasons identified were the inability to afford treatment $(62.86 \%)$, unawareness of treatment (14.29\%), and geographical reasons such as lack of transport to the hospital or having to travel long distances to the hospital $(11.43 \%)$. Other reasons include having no one to accompany them (5.71\%), feeling that treatment was unnecessary $(5.71 \%)$, waiting for a surgical camp (5.71\%), lack of time $(5.71 \%)$, having adequate vision in one eye $(2.86 \%)$, health problems preventing them from going to the hospital $(2.86 \%)$, waiting for their previous cataract operation to heal $(2.86 \%)$, and waiting for the winter season $(2.86 \%)$.
In female subjects with unilateral blindness (VA $<6 / 60$ ), the main barriers identified were the inability to afford treatment (62.22\%), unawareness of treatment (22.22\%), and having no one to accompany them to the hospital $(11.11 \%)$. Other reasons include waiting for cataract to mature $(8.89 \%)$, having adequate vision in one eye $(4.44 \%)$, health problems preventing them from going to the hospital (4.44\%), lack of transport or having to travel long distances to the hospital $(2.22 \%)$, feeling that treatment was unnecessary $(2.22 \%)$, waiting for a surgical camp (2.22\%), waiting for their previous cataract surgery to heal $(2.22 \%)$, and not knowing how to get surgery $(2.22 \%)$.

These results are presented in Table 3 and Figure 2. 
Table 3: The numbers and percentages of each barrier cited by patients with unilateral blindness according to the Nepal definition of blindness $(\mathrm{VA}<6 / 60)$.

\begin{tabular}{|l|c|c|c|c|c|c|}
\hline \multirow{2}{*}{\multicolumn{1}{|c|}{ Barriers }} & \multicolumn{2}{c|}{$\begin{array}{c}\text { Males } \\
\text { total=35) }\end{array}$} & \multicolumn{2}{c|}{$\begin{array}{c}\text { Females } \\
\text { (total =45) }\end{array}$} & \multicolumn{2}{c|}{$\begin{array}{c}\text { Total } \\
\text { (total = 80) }\end{array}$} \\
\cline { 2 - 8 } & $\mathrm{n}$ & $\%$ & $\mathrm{n}$ & $\%$ & $\mathrm{n}$ & $\%$ \\
\hline Cannot afford & 22 & 62.86 & 28 & 62.22 & 50 & 62.50 \\
\hline Unaware of treatment & 5 & 14.29 & 10 & 22.22 & 15 & 18.75 \\
\hline Hospital was too far away/No transport & 4 & 11.43 & 1 & 2.22 & 5 & 6.25 \\
\hline No company & 2 & 5.71 & 5 & 11.11 & 7 & 8.75 \\
\hline Felt that treatment was unnecessary & 2 & 5.71 & 1 & 2.22 & 3 & 3.75 \\
\hline Waiting for surgical camp & 2 & 5.71 & 1 & 2.22 & 3 & 3.75 \\
\hline No time & 2 & 5.71 & 0 & 0.00 & 2 & 2.50 \\
\hline Adequate vision in one eye & 1 & 2.86 & 2 & 4.44 & 3 & 3.75 \\
\hline Health problems & 1 & 2.86 & 2 & 4.44 & 3 & 3.75 \\
\hline Waiting for previous cataract surgery to heal & 1 & 2.86 & 1 & 2.22 & 2 & 2.50 \\
\hline Waiting for winter & 1 & 2.86 & 0 & 0.00 & 1 & 1.25 \\
\hline Waiting for cataract to mature & 0 & 0.00 & 4 & 8.89 & 4 & 5.00 \\
\hline Unaware of how to access treatment & 0 & 0.00 & 1 & 2.22 & 1 & 1.25 \\
\hline
\end{tabular}

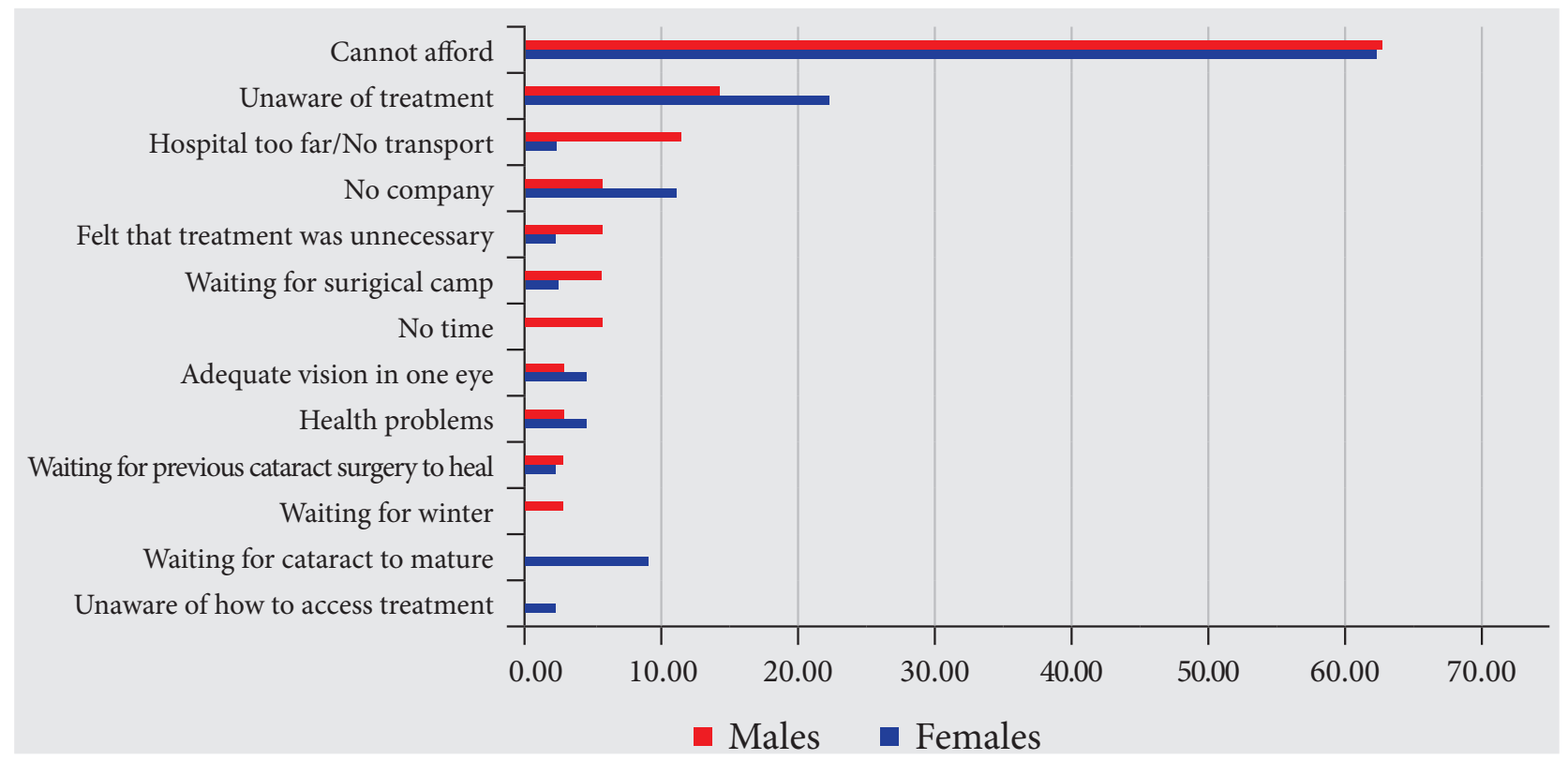

Figure 2: Comparison between the percentages of each barrier cited by male and female subjects with unilateral blindness according to the Nepal definition of blindness $(\mathrm{VA}<6 / 60)$. 
Table 4: The numbers and percentages of each barrier cited by patients with bilateral blindness according to the WHO definition of blindness $(\mathrm{VA}<3 / 60)$.

\begin{tabular}{|l|c|c|c|c|c|c|}
\hline \multirow{2}{*}{\multicolumn{1}{c|}{ Barriers }} & \multicolumn{2}{c|}{ Male (total = 7) } & \multicolumn{2}{c|}{ Female (total = 5) } & \multicolumn{2}{c|}{ Total (total = 12) } \\
\cline { 2 - 7 } & $\mathbf{n}$ & $\mathbf{\%}$ & $\mathbf{n}$ & $\mathbf{\%}$ & $\mathbf{n}$ & $\mathbf{\%}$ \\
\hline Cannot afford & 6 & 85.71 & 3 & 60.00 & 9 & 75.00 \\
\hline Unaware of treatment & 2 & 28.57 & 0 & 0.00 & 2 & 16.67 \\
\hline Adequate vision in one eye & 0 & 0.00 & 1 & 20.00 & 1 & 8.33 \\
\hline Waiting for cataract to mature & 0 & 0.00 & 1 & 20.00 & 1 & 8.33 \\
\hline
\end{tabular}

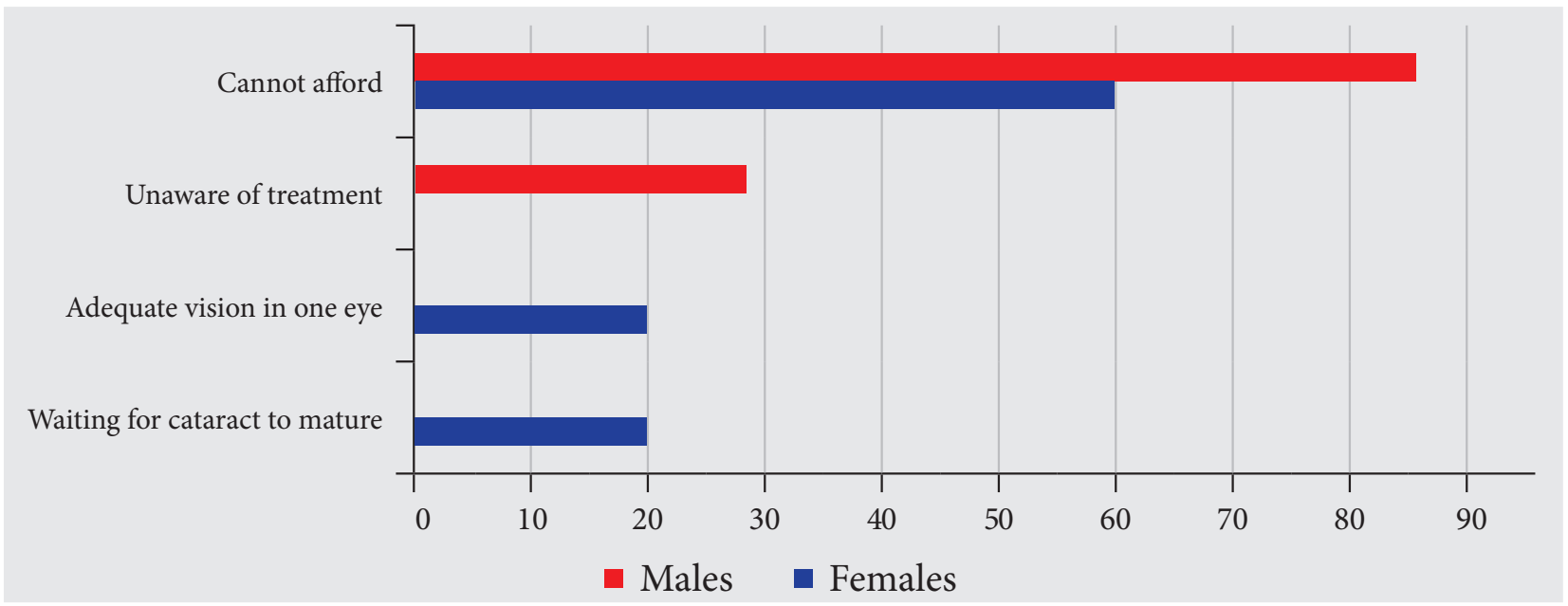

Figure 3: Comparison between the percentages of each barrier cited by male and female subjects with bilateral blindness according to the WHO definition of blindness $(\mathrm{VA}<3 / 60)$.

Bilateral blindness (WHO definition, visual acuity $<3 / 60$ in both eyes)

In male subjects with bilateral blindness (VA $<3 / 60$ ), the main reasons identified were the inability to afford treatment (85.71\%), and unawareness of treatment $(28.57 \%)$.

In female subjects with bilateral blindness $(\mathrm{VA}<3 / 60)$, the main reasons identified were the inability to afford treatment $(60.00 \%)$, unawareness of treatment (20.00\%), and waiting for cataract to mature $(20.00 \%)$.
These results are presented in Table 4 and Figure 3.

Bilateral blindness (Nepal definition, visual acuity $<6 / 60$ in both eyes)

In male subjects with bilateral blindness (VA $<6 / 60$ ), the main barriers identified were the inability to afford treatment (83.33\%) and being unaware of treatment $(16.67 \%)$. Other reasons include having adequate vision in one eye (5.56\%), having no one to accompany them to the hospital (5.56\%), and fear of operation (5.56\%). 
For female subjects with bilateral blindness (VA $<6 / 60$ ), the main barriers identified were the inability to afford treatment $(66.67 \%)$ and being unaware of treatment $(22.22 \%)$. Other reasons include waiting for their cataract to mature $(11.11 \%)$, having adequate vision in one eye $(5.56 \%)$, having no one to accompany them to the hospital $(5.56 \%)$, health problems preventing them from going to the hospital $(5.56 \%)$, feeling that treatment was unnecessary $(5.56 \%)$, and being unaware of how to access treatment $(5.56 \%)$.

These results are presented in Table 5 and Figure 4.

Table 5: The numbers and percentages of each barrier cited by patients with bilateral blindness according to the Nepal definition of blindness $(\mathrm{VA}<6 / 60)$.

\begin{tabular}{|l|c|c|c|c|c|c|}
\hline \multirow{2}{*}{\multicolumn{1}{|c|}{ Barriers }} & \multicolumn{2}{|c|}{ Male (total = 18) } & \multicolumn{2}{l|}{ Female (total = 18) } & \multicolumn{2}{c|}{ Total (total = 36) } \\
\cline { 2 - 7 } & $\mathrm{n}$ & $\%$ & $\mathrm{n}$ & $\%$ & $\mathrm{n}$ & $\%$ \\
\hline Cannot afford & 15 & 83.33 & 12 & 66.67 & 27 & 75.00 \\
\hline Unaware of treatment & 3 & 16.67 & 4 & 22.22 & 7 & 19.44 \\
\hline Adequate vision in one eye & 1 & 5.56 & 1 & 5.56 & 2 & 5.56 \\
\hline No company & 1 & 5.56 & 1 & 5.56 & 2 & 5.56 \\
\hline Fear of operation & 1 & 5.56 & 0 & 0.00 & 1 & 2.78 \\
\hline Waiting for cataract to mature & 0 & 0.00 & 2 & 11.11 & 2 & 5.56 \\
\hline Health problems & 0 & 0.00 & 1 & 5.56 & 1 & 2.78 \\
\hline Felt that treatment was unnecessary & 0 & 0.00 & 1 & 5.56 & 1 & 2.78 \\
\hline Unaware of how to access treatment & 0 & 0.00 & 1 & 5.56 & 1 & 2.78 \\
\hline
\end{tabular}

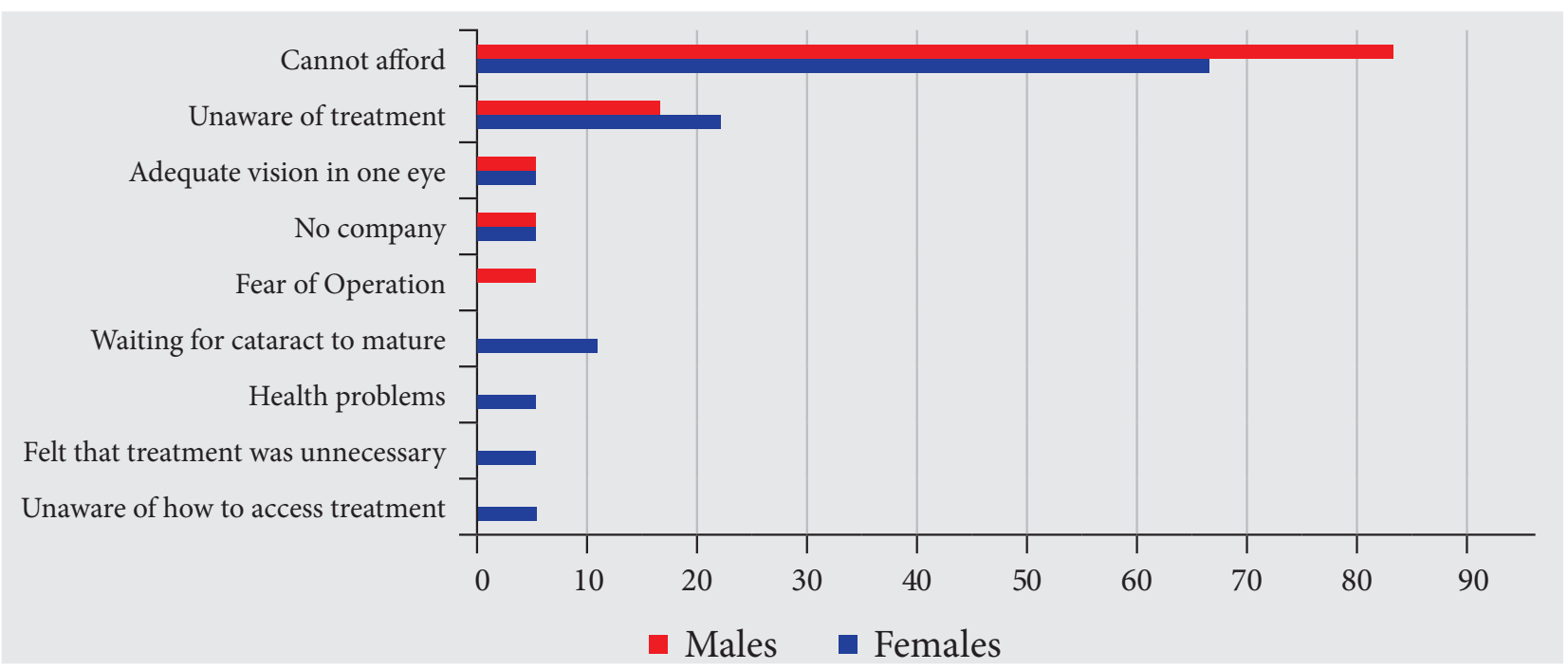

Figure 4: Comparison between the percentages of each barrier cited by male and female subjects with bilateral blindness according to the Nepal definition of blindness $(\mathrm{VA}<6 / 60)$. 
Table 6: Numbers and percentages of answers by male and female subjects (regardless of presenting visual acuity) for questions regarding the causes and treatment of cataract.

\begin{tabular}{|c|c|c|c|c|c|c|c|}
\hline \multirow{2}{*}{ Question } & \multirow{2}{*}{ Answer } & \multicolumn{2}{|c|}{ Male } & \multicolumn{2}{c|}{ Female } & \multicolumn{3}{c|}{ Total } \\
\cline { 3 - 9 } & & $\mathrm{n}$ & $\%$ & $\mathrm{n}$ & $\%$ & $\mathrm{n}$ & $\%$ \\
\hline \multirow{2}{*}{ Do you know about the causes of cataract? } & Yes & 20 & 31.7 & 15 & 24.2 & 35 & 28.0 \\
\cline { 2 - 9 } & No & 43 & 68.3 & 47 & 75.8 & 90 & 72.0 \\
\hline \multirow{2}{*}{ Do you know that cataract can be treated? } & Yes & 33 & 46.5 & 38 & 45.8 & 71 & 46.1 \\
\cline { 2 - 9 } & No & 38 & 53.5 & 45 & 54.2 & 83 & 53.9 \\
\hline
\end{tabular}

\section{Awareness of the Causes and Treatment of}

\section{Cataract}

A higher percentage of female subjects (75.8\%) did not know the causes of cataract compared to male subjects $(68.3 \%)$. Similarly, when asked if they knew that cataract could be treated, a higher percentage of female subjects $(54.2 \%)$ did not know compared to male subjects $(53.5 \%)$. These results are presented in Table 6.

\section{DISCUSSION}

Identifying and understanding the barriers that prevent patients from accessing cataract surgery is key to improving eye care in Nepal. As people in different regions often face differing barriers to healthcare, it is necessary to conduct studies specific to individual regions. This study aims to identify the barriers to cataract surgery faced by the population in Morang and Sunsari districts, so as to facilitate the regional development of access to cataract services.

\section{Main Findings}

In this study, patients who attended a surgical camp for cataract were surveyed. Subjects were asked questions about the reasons for their delay in treatment and their awareness about cataract as a disease.

Globally, as well as in Nepal, the inability to afford treatment has been reported as the largest barrier to cataract surgery in various regions for all patients (both subjects with unilateral blindness and bilateral blindness) (Sapkota et al, 2004, 2012; Tabin et al, 2007). Our study was consistent with this, with the majority of patients citing financial reasons as the principal cause of their delay in treatment (both $\mathrm{VA}<3 / 60$ and VA $<6 / 60$ ). Citing financial reasons means that the subject was keen to undergo surgery but was unable to do so due to financial constraints.

However, financial reasons were not always the main barrier to cataract surgery in Morang and Sunsari districts. Data gathered in 2012 from the previous Koshi Zone (which included the Morang and Sunsari Districts as well as the surrounding hills and mountains) identified the lack of available services (16\%) and having adequate vision in one eye $(16 \%)$ as the main 
barriers faced by subjects with unilateral blindness (Nepal definition, VA <6/60) (Sapkota et al, 2012). In subjects with bilateral blindness (Nepal definition, VA $<6 / 60$ ), feeling that treatment was unnecessary (21\%) and being unaware of how to access surgery (18\%) were the main barriers reported.

The transition of main barriers from the aforementioned barriers in 2012 to financial reasons in 2018 signifies three things. Firstly, cataract surgery is now more widely available in Morang and Sunsari, resulting in the lack of available services in the area to no longer be a significant barrier. Secondly, awareness of cataract and its treatments has increased in the community, resulting in fewer people feeling that treatment is unnecessary, more people knowing how to access treatment and hence more people wanting to access treatment. Lastly, despite these improvements in availability and awareness of cataract services, a proportion of the population are still unable to access cataract surgery due to their inability to afford treatment.

This transition is similar to that experienced in other regions of Nepal in the past. A study conducted in Kathmandu Valley in 2004 showed that even when subjects were fully aware and in reach of cataract treatment, $56.4 \%$ of subjects were not willing to pay for surgery, with $44 \%$ of those not willing to pay citing poverty as their primary reason (Shrestha et al, 2004).

This shows a similar progression to the development of access to cataract surgery in Morang and Sunsari, where increases in awareness and available services were not followed by a proportional increase in the patient's ability to pay for treatment. This led to many patients, who are keen to undergo treatment, not being able to access treatment solely due to their inability to afford it. Therefore, in order to further increase the CSC in Morang and Sunsari, approaches that specifically address financial barriers should be adopted, so as to ensure that those who are unable to afford treatment are not left out.

There are several methods proposed to address the financial barriers to cataract surgery. The costs of cataract surgery include both direct and indirect costs, with direct cost being the cost for the surgery itself, and indirect costs referring to the costs of transport, accommodation and meals. A systematic review of barriers to cataract surgery in Africa suggests that increasing the productivity of cataract surgery services and implementing a tiered payment system, where costs borne by the patient is adjusted based on income with the remainder being subsidised, can be helpful in reducing direct costs (Aboobaker et al, 2016). To reduce indirect costs, more outreach programmes, where outreach teams go into the communities to screen and transport a busload of cataract patients back to the hospital for surgery, could be implemented.

Nonetheless, while financial barriers are the main barrier to accessing cataract surgery in the Morang and Sunsari districts, there were also several other barriers cited by smaller percentages of subjects, including feeling that 
treatment was unnecessary and not knowing how to access cataract surgery. This demonstrates that there is still room for improvement in increasing awareness of cataract and its treatments in the community.

\section{Differences in Access to Cataract Surgery}

\section{Between Men and Women}

According to the Nepal Epidemiology of Blindness (Sapkota et al, 2012), the total prevalence of bilateral cataract in the Koshi Zone in 2012 according to the WHO definition of blindness (VA < 3/60) was 2,817 [766 males (27.19\%), 2051 females (72.81\%)]. According to the Nepal definition of blindness (VA $<$ $6 / 60)$, the total prevalence was 6,991 [1930 males (27.61\%), 5061 females (72.39\%)]. Upon comparing the above proportions to the proportions of male and female patients with bilateral blindness due to cataract receiving surgery at our surgical camp, it is evident that the proportion of males and females receiving treatment is extremely unrepresentative of the population.

However, it is important to note that the percentages of male and female patients with bilateral blindness due to cataract receiving surgery at the camp might be less representative of the population due to the lower numbers of those surveyed compared to either the WHO definition of blindness or the Nepal definition of blindness.

When using the WHO definition of blindness $(\mathrm{VA}<3 / 60), 58.33 \%$ of patients with bilateral cataract who received treatment at the camp were male and $41.67 \%$ were female. In contrast, epidemiologic data suggests that of those with bilateral cataract in the Koshi Zone, 27.19\% are male and $72.81 \%$ are female.

The same is true when using the Nepal definition of blindness (VA $<6 / 60$ ), where $50 \%$ of subjects who received treatment at the camp were male and $50 \%$ were female. In contrast, the population prevalence study of the Koshi Zone reports that $27.61 \%$ of people with bilateral blindness due to cataract were men and $72.39 \%$ were female.

These findings demonstrate that there are some differences in the ability of males and females to access treatment. Specifically, males are able to access cataract surgery more often than females, leading to the stark differences in the number of people with bilateral blindness due to cataract and the number of people receiving treatment between both genders.

These findings are consistent with the current literature, with several studies supporting it. As mentioned above, of people with bilateral blindness due to cataract in the Koshi Zone, $72.39 \%$ were females and $26.71 \%$ were males (Nepal definition, VA $<6 / 60$ ). Yet, the Cataract Surgical Coverage (Persons, VA < 6/60) in 2012 for the Koshi Zone was $57.50 \%$ for females and $72.50 \%$ for males (Sapkota et al, 2012). A study by Pradhan et al (2018) supports this, reporting that although women accounted for a far greater proportion of people with bilateral blindness $(\mathrm{VA}<6 / 60)$ due to cataract, cataract surgical coverage "continues to favour men" in Nepal. 
Furthermore, a systematic review by Lewallen et al (2002) showed that in Nepal, the odds ratio of women with cataract receiving treatment compared to men was 0.63 (95\% confidence interval $=[0.61,0.66])$. Another study by Lewallen et al (2009) showed that the odds ratio of men receiving cataract surgery compared women was 1.94 (95\% confidence interval= $[1.10,3.44])$.

There are several possible reasons for this gender difference in cataract surgical coverage. Firstly, women may have lower levels of awareness about cataract as a disease compared to men. From our surveys, a greater percentage of women were unaware of the causes [female $=$ $75.8 \%$, male $=68.3 \%$ ] and available treatments [female $=54.2 \%$, male $=53.5 \%$ ] of cataract compared to men. The decreased level of awareness of the causes of cataract may lead to women using fewer protective measures against cataract such as sunglasses compared to men, resulting in a greater number of women having cataract compared to men. In addition, a lower awareness of the available treatments for cataract could lead to a lower number of women opting for surgery.

These gender differences could also be attributed to lower acceptance rates of surgery by women. A study by Snellingen et al (1998) on the socioeconomic barriers to cataract surgery in Nepal reported that although females were more likely to have visual impairments due to cataract than men, surgery was more readily accepted by men. Snellingen suggests that this was probably the result of the differences in gender roles between males and females, with males being more mobile and females being traditionally more confined to the household.

If the CSC were equal in men and women, an additional 3085 women would have been operated on in 2002 , equivalent to $4.0 \%$ of the blind in Nepal (Lewallen et al, 2002). Therefore, tackling the issue of unequal coverage between men and women would be a very effective way of decreasing the prevalence of avoidable blindness due to cataract and increasing the CSC in Nepal.

To tackle this, Lewallen suggests that adopting gender-specific, community-based education programmes about cataract would be effective in raising the awareness and knowledge of cataract amongst women (Lewallen et al, 2002). Through raising awareness, these programmes would increase the rate of acceptance of treatment by women and facilitate the closing of the gap in CSC. Furthermore, women who know other women who had undergone successful cataract surgeries themselves were more likely to undertake surgeries. Therefore, assuming that surgical outcomes are good, helping more women access surgery would result in a selfperpetuating positive effect in increasing CSC for women.

\section{Limitations}

Potential limitations of our study could affect the generalizability and the accuracy of our results. 
- Selection bias: the survey was conducted on subjects who opted to attend a free-ofcharge surgical camp, and not randomly, which would have included those who opted to not go for surgery or were unaware of the screening camps.

- Higher proportion of subjects citing inability to afford treatment: the surgical camp was meant to target populations that were unable to access cataract surgery due to their inability to afford surgery and consequently, the proportion of other reasons as the principle barrier to be lower than expected. Surveys could have been done at a screening level instead of a post-treatment scenario for a more accurate representation of the population.

- Dishonesty about true reasons for delay in treatment: A study in Africa found that asking patients for the reasons for not having surgery earlier can be extremely sensitive (Aboobaker et al, 2016). Likewise, the Nepal Epidemiology of Blindness explains that the procedure of asking patients for the "reasons why they have not been operated on yet is not ideal" as the interviewer is not seen as a "neutral person". Therefore, subjects may give an answer that would not cause embarrassment or be challenged by the interviewer, such as the inability to afford treatment. Interviewer training with more neutral forms of questioning may be useful in mitigating this issue.

\section{Future Direction}

In our literature review, there were very few recent studies found on the barriers to cataract surgery in specific areas of Nepal. A larger number of studies determining the barriers to cataract surgeries in specific areas need to be conducted at a more frequent rate, as they serve both to reflect the effectiveness of implemented policies and act as a platform for the development of new ones.

\section{CONCLUSION}

The most prevalent barrier to cataract surgery faced by the population in Morang and Sunsari districts is the inability to afford treatment. Second to this, a lack of awareness that cataract is treatable also prevents a significant proportion of people from receiving the care they require. To overcome this, policies aiming to reduce the financial barriers to cataract surgery should be introduced, while continuing to raise awareness about cataract surgery through the implementation of various outreach and community education programmes.

If continued efforts are made to surmount the various barriers identified in this study, access to cataract surgery will surely increase and the prevalence of blindness due to cataract will decrease, bringing Nepal one step closer towards achieving its goal of eliminating avoidable blindness in the country.

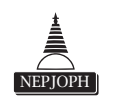




\section{REFERENCES}

Aboobaker S, Courtright P (2016). Barriers to Cataract Surgery in Africa: A Systematic Review. Middle East African journal of ophthalmology. Jan-Mar; 23 (1):145-9. doi: 10.4103/0974-9233.164615

Brilliant LB, Pokhrel RP, Grasset NC, Lepkowski JM, Kolstad A, Hawks W, et al (1985). Epidemiology of blindness in Nepal. Bulletin of the World Health Organization. 63(2):375-86.

Flaxman SR, Bourne RRA, Resnikoff S, et al (2017). Global causes of blindness and distance vision impairment 1990-2020: a systematic review and meta-analysis. The Lancet Global Health. 5(12):e1221-e34. doi: 10.1016/ S2214-109X(17)30393-5

Gray Z, P A (2015). Cataract Surgical Coverage. International Agency for the Prevention of Blindness: International Agency for the Prevention of Blindness.

Lewallen S, Courtright P (2002). Gender and use of cataract surgical services in developing countries. Bulletin of the World Health Organization. 80 (4):300-3.

Lewallen S, Mousa A, Bassett K, Courtright P (2009). Cataract surgical coverage remains lower in women. The British journal of ophthalmology. 93(3):295-8. doi: 10.1136/bjo.2008.140301

Pradhan S, Deshmukh A, Giri Shrestha P, Basnet P, Kandel RP, Lewallen S, et al (2018). Prevalence of blindness and cataract surgical coverage in Narayani Zone, Nepal: a rapid assessment of avoidable blindness (RAAB) study. British Journal of Ophthalmology. 102(3):291-4. doi: 10.1136/bjophthalmol-2017-310716

Polack S, Eusebio C, Mathenge W, Wadud Z, Rashid M, Foster A, et al (2010). The Impact of Cataract Surgery on Activities and Time-Use: Results from a Longitudinal Study in Kenya, Bangladesh and the Philippines. PLOS ONE. 5(6):e10913. doi: 10.1371/journal.pone.0010913

Sapkota Y, Hans L (2012). Epidemiology of Blindness in Nepal.

Sapkota YD, Pokharel GP, Dulal S, Byanju RN, Maharjan IM (2004). Barriers to up take cataract surgery in Gandaki Zone, Nepal. Kathmandu University medical journal (KUMJ). 2(2):103-12.

Shrestha MK, Thakur J, Gurung CK, Joshi AB, Pokhrel S, Ruit S (2004). Willingness to pay for cataract surgery in Kathmandu valley. The British journal of ophthalmology. 88(3):319-20. doi: 10.1136/bjo.2003.026260

Snellingen T, Shrestha BR, Gharti MP, Shrestha JK, Upadhyay MP, Pokhrel RP (1998). Socioeconomic Barriers to Cataract Surgery in Nepal: The South Asian Cataract Management Study. The British journal of ophthalmology. 82(12):1424-8. doi: 10.1136/bjo.82.12.1424

Tabin G, Chen M, Espandar L (2008). Cataract Surgery for the Developing World. Current Opinion in Ophthalmology. 19(1):55-9. doi: 10.1097/ICU.0b013e3282f154bd

World Health Organization (2016). International Statistical Classification of Diseases and Related Health Problems 10th Revision.

World Health Organization. (2013)! Universal eye health: a global action plan 2014-2019. Available from: https:// apps.who.int/iris/handle/10665/105937

Wong, T.Y., 2006. The epidemiology of age related eye diseases in Asia. British Journal of Ophthalmology, 90(4), pp.506-511. 